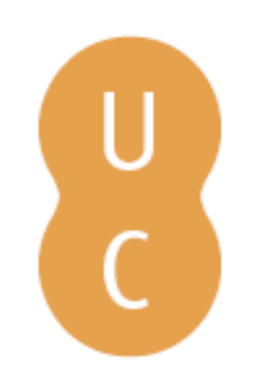

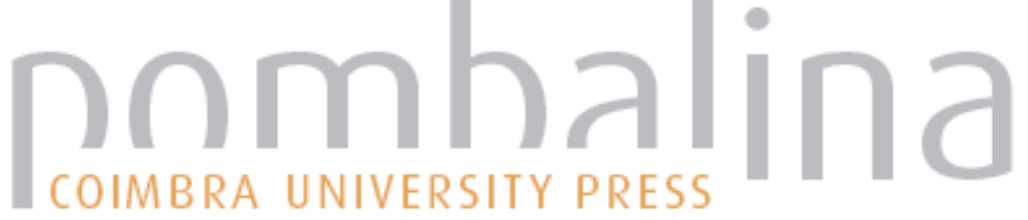

\section{Assessing the increase in wildfire occurrence with climate change and the uncertainties associated with this projection}
Autor(es):
Fargeon, Hélène; Martin-StPaul, Nicolas; Pimont, François; Cáceres, Miquel De; Ruffault, Julien; Opitz, Thomas; Allard, Denis; Dupuy, Jean- LuC

Publicado por: Imprensa da Universidade de Coimbra

URL persistente:

URI:http://hdl.handle.net/10316.2/44519

DOI:

DOI:https://doi.org/10.14195/978-989-26-16-506_2

Accessed : $\quad$ 26-Apr-2023 09:57:31

A navegação consulta e descarregamento dos títulos inseridos nas Bibliotecas Digitais UC Digitalis, UC Pombalina e UC Impactum, pressupõem a aceitação plena e sem reservas dos Termos e Condições de Uso destas Bibliotecas Digitais, disponíveis em https://digitalis.uc.pt/pt-pt/termos.

Conforme exposto nos referidos Termos e Condições de Uso, o descarregamento de títulos de acesso restrito requer uma licença válida de autorização devendo o utilizador aceder ao(s) documento(s) a partir de um endereço de IP da instituição detentora da supramencionada licença.

Ao utilizador é apenas permitido o descarregamento para uso pessoal, pelo que o emprego do(s) título(s) descarregado(s) para outro fim, designadamente comercial, carece de autorização do respetivo autor ou editor da obra.

Na medida em que todas as obras da UC Digitalis se encontram protegidas pelo Código do Direito de Autor e Direitos Conexos e demais legislação aplicável, toda a cópia, parcial ou total, deste documento, nos casos em que é legalmente admitida, deverá conter ou fazer-se acompanhar por este aviso.

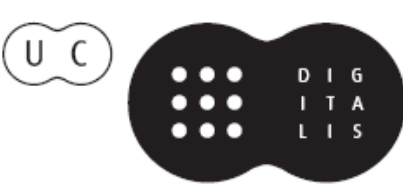




\section{ADVANCES IN}

\section{FOREST FIRE RESEARCH}

\section{8}

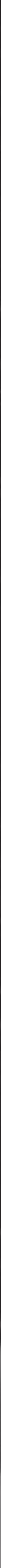




\title{
Assessing the increase in wildfire occurrence with climate change and the uncertainties associated with this projection
}

\author{
Hélène Fargeon ${ }^{1 *}$; Nicolas Martin-StPaul ${ }^{1}$; François Pimont ${ }^{1}$; Miquel De Cáceres ${ }^{2}$; Julien \\ Ruffault $^{3}$; Thomas Opitz ${ }^{4}$; Denis Allard ${ }^{4}$; Jean-Luc Dupuy ${ }^{1}$ \\ 1*URFM INRA, 84914 Avignon, France. \{helene.fargeon@inra.fr*,nicolas.martin@inra.fr, \\ nicolas.martin@inra.fr, jean-luc.dupuy@inra.fr \} \\ ${ }^{2}$ CTFC, 25280 Solsona, Spain. \{miquelcaceres@gmail.com\} \\ ${ }^{3}$ IMBE, 13290 Aix-en-Provence France.\{julien.ruff@gmail.com\} \\ ${ }^{4}$ BioSP INRA, 84914 Avignon, France. \{thomas.opitz@inra.fr, denis.allard@inra.fr \}
}

\begin{abstract}
According to climate projections, global warming is associated with increasing temperatures and dry spells in some parts of the world, especially the Mediterranean area. This climate change has already triggered increases in wildfire danger and fire season length in Southern Europe and is expected to amplify in the forthcoming decades. However, it is quite challenging for the scientific community to assess the intensity of these changes, because (i) the trend relies on the greenhouse gases (GHG) emission scenario and (ii) fire occurrence depends on multiple factors (including climate, but not only). A proper assessment of the trend in terms of fire occurrence and of uncertainties associated with this increasing trend, still lacks, especially for the French territory.

Our study refines traditional approaches of fire risk projection under climate change on two aspects: (i) the impact of climate prediction uncertainties on the prediction of fire danger, and (ii) the translation of a danger index into a fire occurrence (per size classes).
\end{abstract}

Keywords: climate change, uncertainties, fire danger

\section{Introduction}

The impact of climate change on wildfire danger has been extensively studied in different parts of the world. The traditional approach consists in projecting climatic danger indices like the Fire Weather Index (FWI) or its subcomponents. The FWI System is a fire danger rating system designed by the Canadian Forestry Service (Van Wagner 1987). It models the moisture content of three classes of forest fuel and combines it with the effect of wind on fire behaviour. It is noticeable that the FWI System refers primarily to a standard fuel pine type but has been widely used as a general measure of forest fire danger, even in areas with climate and vegetation markedly differing from that in Canada. Yet, a link between high FWI values and observed fire occurrences has been shown in the Mediterranean context (Good et al. 2008; Viegas et al. 1999). Regarding climate change, some studies have projected FWI at Europe scale for various GHG emission scenarios (Moriondo et al. 2006; Bedia et al. 2014a) and various climate models, predicting an increase in overall FWI values and a change in the length of the fire season (Moriondo et al. 2006). Many FWI projections have also been produced at country or regional scale in Europe. However, few studies address the origin of the uncertainties in these projections: can we separate the uncertainty coming from the climate model and the uncertainty coming from the scenario choice, and which one is predominant? Does this partition vary during the time period of interest? In a first step, we project future FWI and attempt to evaluate the resulting uncertainties for France. The interpretation of FWI projections in terms of future fire activity with metrics such as expected fire number or burnt area (e.g. Amatulli et al. 2013) is challenging. Indeed, FWI is not a straightforward proxy for fire activity, as its response function is often unknown and as a 
lot of other factors interact to determine fire activity (Bedia et al. 2014b): ignition patterns and fuel availability are linked to land use and land cover, to vegetation adaptation to climate change, to population density and awareness to the risk, fire prevention policies, etc. As a result, interpreting temporal and spatial averages of FWI (or of derived metrics of the FWI such as number of days above a certain threshold) is challenging. For example, it is not straightforward to interpret the exact meaning of a 10\% increase in the average of FWI over given territories and time periods, in terms of quantification of fire activity evolution. In the present study, we develop a statistical model to predict fire occurrence as a function of daily FWI and a few other factors for Southern France and project the fire occurrence under future climate, in order to facilitate the interpretation of FWI projection under future climate.

\section{Assessing future climatic fire danger and its uncertainties}

\subsection{Increasing droughts and temperatures}

To simulate the evolution of climate over France during the coming century, we used simulations output from five couples of global and regional climate models (GCM-RCM), with two IPCC scenarios (rcp4.5 and rcp8.5) at ca. $0.5^{\circ}$ spatial resolution. GCM-RCM pairs were chosen according to the synthesis of McSweeney et al 2014, to be the most realistic while providing a contrasted range of projections for temperature and precipitation amount, two climate variables especially involved in fire probability. This was done in order to encompass the whole range of predictions with a minimum of models.

A bias correction and downscaling was performed using quantile mapping and anomaly method with R package "meteoland" (De Cáceres et al. 2017). The 8-km-resolution-SAFRAN reanalysis (Vidal et al. 2010) was used as reference data. The FWI, widely used to forecast climatic fire danger, was then computed for all the daily climate series for the period 2005-2100, using package "cffdrs" (Wang et al. 2017).

All models converged toward an increase in FWI during the $21^{\text {st }}$ century (Figure 1). The projections nevertheless differed in terms of intensity, with some models predicting harder conditions than others in accordance with our prior model selection.

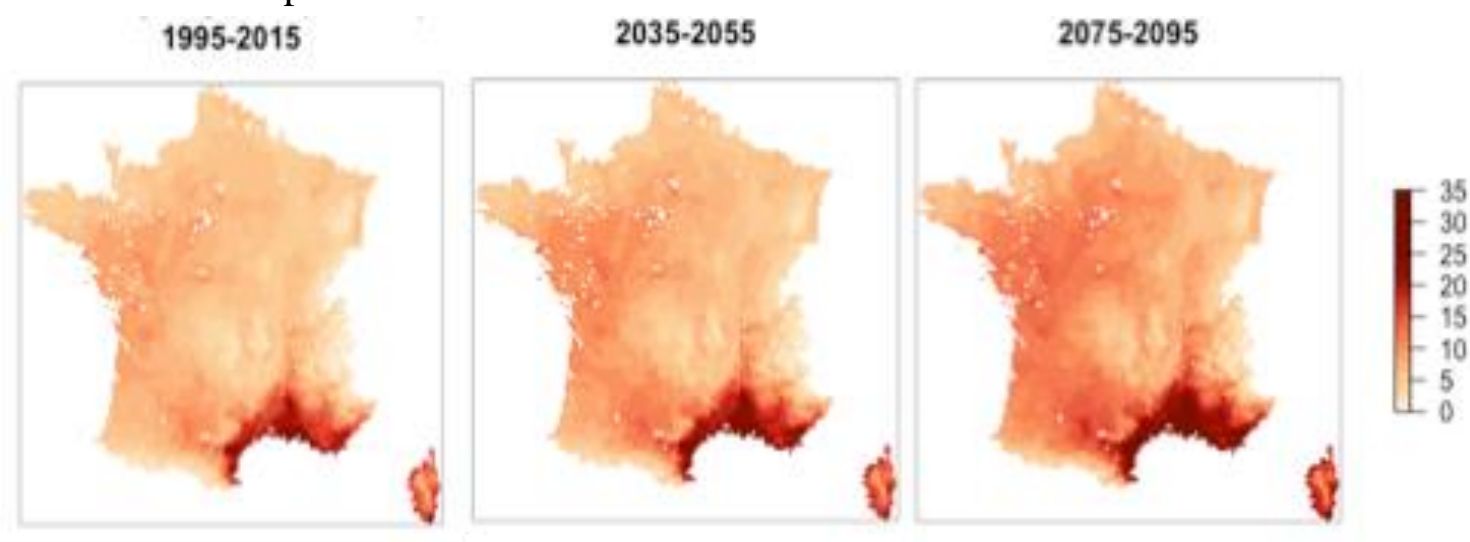

Figure 1 - Evolution of the mean FWI during fire season (June-September) for different time horizons. Each map corresponds to an average between models and scenarios. They show an overall increase in FWI values over the period.

\subsection{Uncertainties about the projections}

We distinguish three different sources of uncertainties, following the approach developed in (Hawkins and Sutton 2009). The inter-annual variability of the climatic danger, calculated as the variation of annual mean values with respect to a trend defined as a 30-year moving average, is called "internal variability". We consider this internal variability as constant during the whole time-period. 
A second source of uncertainty, called "model uncertainty", comes from the differences between the trends of the different models. Finally, the last source of uncertainty we considered derived from differences in GHG emission scenarios and is calculated as the difference between the multimodel mean values given respectively by scenario rcp 4.5 and by scenario rcp8.5 ("scenario uncertainty").

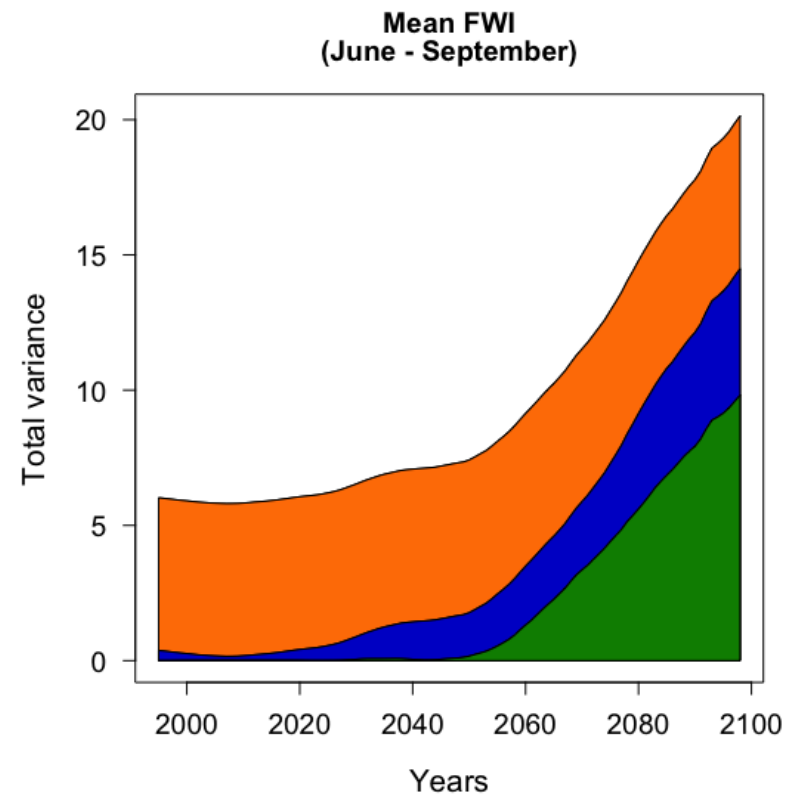

Figure 2 - Proportion of the different contribution to total variance in mean future annual FWI predictions during fire season. Internal variability contribution is in orange, model uncertainty in blue, and scenario uncertainty in green.

Internal variability remains the major source of overall variance in the prediction until the 2050s (Figure 2). In the second half of the century, overall variance begins to increase at an important pace, thanks to growing model and scenario uncertainty. This almost leads to a fourfold increase of the total variance in 2100 as compared to 2000.

\section{Projecting the fire occurrence in Southern France}

\subsection{Linking past fires with past weather conditions through a statistical model}

The next step of our approach consists in transforming FWI projections into expected wildfire occurrence, i.e. number of fires (per size classes, i.e. above some threshold for burnt area) per day and $\mathrm{km}^{2}$. In the fire-prone French Mediterranean area, data showed that observed fire occurrence (derived from the Prométhée database) clearly increased with daily FWI (computed with SAFRAN reanalysis), which confirms the relevance of FWI projection for the evaluation of climate change impacts on fire risk. However, the wildfire occurrence does not increase linearly with FWI and is also strongly affected by other temporal and spatial factors (Figure 3), which raises some concerns regarding the interpretation of projections. 


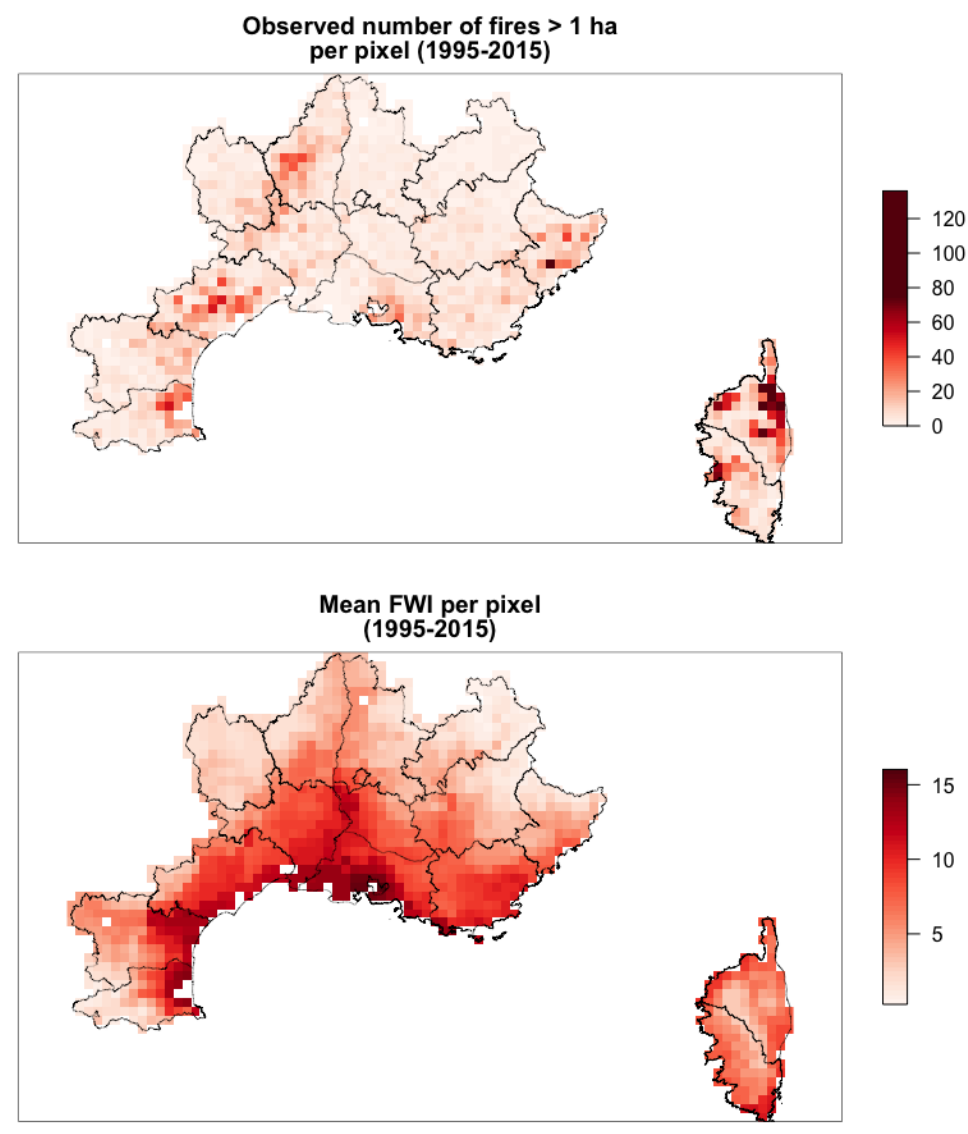

Figure 3 - Spatial distribution of observed fires above 1 ha burnt area in French Mediterranean area (Prométhée database), compared with the distribution of mean annual FWI values per pixel during the same time period. Wildfire occurrence appears to be strongly affected by spatial factors.

With this in mind, we developed a probability-based model for predicting the daily expected number of forest fires above 1 ha burnt area as a function of explanatory variables like FWI, season and location. The approach is adapted from the framework developed to model the probability of fire occurrence in (Brillinger et al. 2003; Preisler et al. 2004). Here we had to group our data into spatialtemporal cells $\left(64 \mathrm{~km}^{2}\right.$-day cell level), so that the logistic model used in the original studies was replaced by the Poisson model, fitting a non-parametric Poisson model with log-additive intensity to the data. Aside from the FWI, we estimate partial multiplicative effects of other variables, selected to better represent data features that are not well represented (e.g. seasonal pattern), or not represented at all (e.g. spatial effects such as proximity to urban interfaces and networks) in the definition of the FWI. The form of the model is described in Equation (1), where $S$ refers to the forested area in the pixel. The model is adjusted using integrated nested Laplace approximations (INLA) described in (Rue et al. 2009; Lindgren and Rue 2015).

$$
\text { Fire number }=\text { Intercept } * S * f(S) * g(F W I) * h(\text { Week }) * i(\text { Pixel })
$$

The partial effects of each variable on fire occurrence according to the statistical model are presented in Figure 4 and Figure 5. 

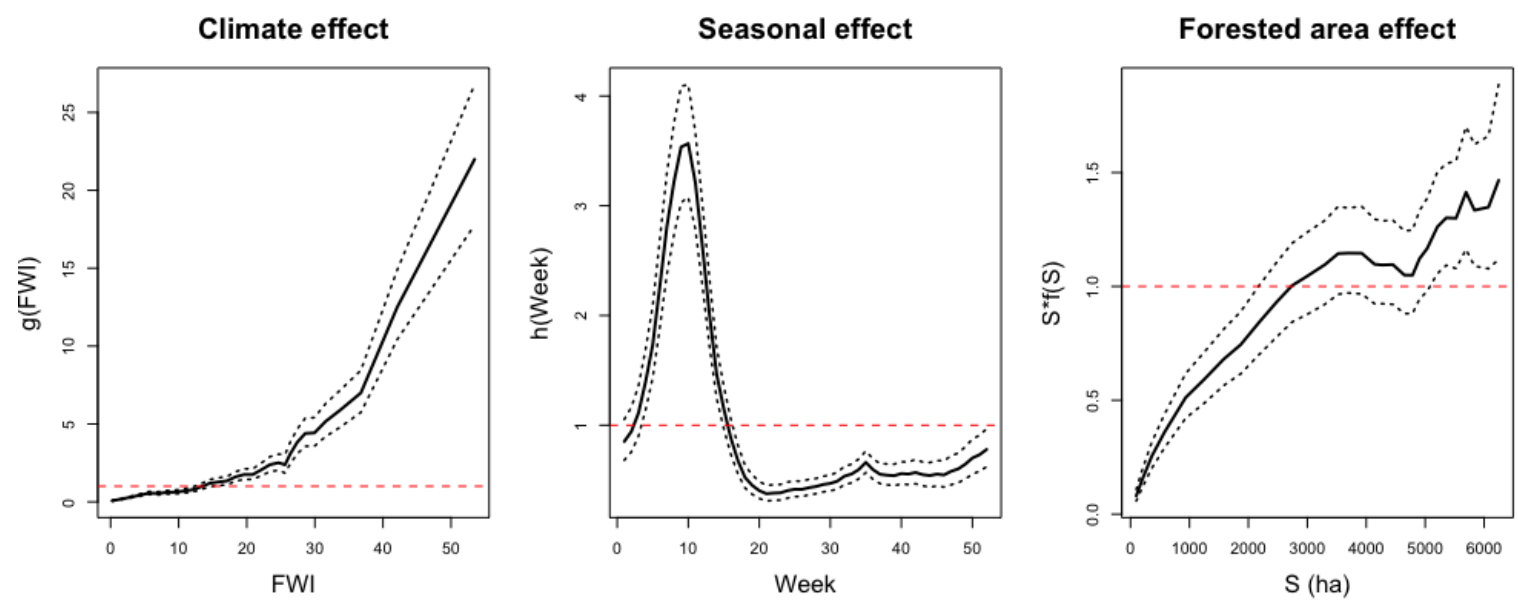

Figure 4 - Partial effects of the statistical climate-fire model. From left to right, we show the effects of daily $F$ WI (surrogate for climate effect), season (week of the year) and forested area on the number of fires above 1 ha burnt area per day and per $\mathrm{km}^{2}$. Low values indicate an inhibition effect on fire occurrence, while high values show an enhancement.

The link between high FWI and high fire occurrence is confirmed and exhibits a clear non-linear response function. Importantly, such non-linear shape of the function makes it tricky to interpret the FWI directly in terms of fire occurrence: it is not the same to have one day at FWI $=5$ and one day at $\mathrm{FWI}=45$, compared to 2 days at FWI $=25$. The expected number of fire will be much larger in the first than in the second scenario, because of the convexity of the response function.

Concerning seasonal relative fire risk, a peak in fires associated to early spring is noticeable, not well addressed by the FWI alone. This seasonal effect is probably related to the seasonality of live fuel moisture. An FWI of 10 in March will correspond to a much larger number of actual fires than in June, which again raises the question of the significance of the FWI.

Fire occurrence increases with increasing forested area, as expected since the surface area available for ignition increases. However, a saturation of occurrence is observed for high forested areas and can be interpreted as an effect of lower population and infrastructure densities in densely forested pixels, resulting in a lower human ignition pressure.

\section{Spatial effect}

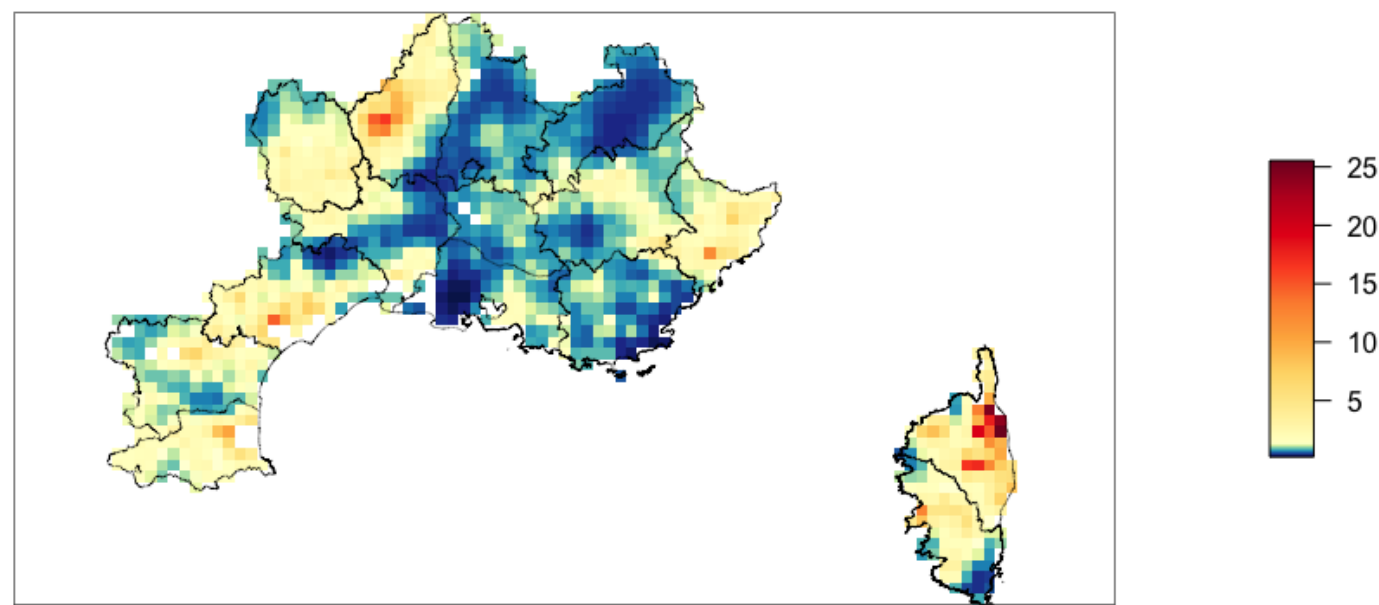

Figure 5 - Effect of spatial location on the number of fires above 1 ha burnt area per day and per $\mathrm{km}^{2}$. High variability is visible, with some hotspots of expected fires that cannot be explained by the other explanatory variables included in the model. 
A remaining spatial pattern, which accounts for regional variations that are not explained by the other factors, also exhibits a strong influence on fire occurrence. Indeed, the geographic position is the only other explanatory variable which explains variation in fire occurrence with amplitudes comparable to the FWI effect.

Using this generative model to simulate expected fires under past conditions, we can try to unveil hidden explanatory variables like human action. This has been done in Figure 6.

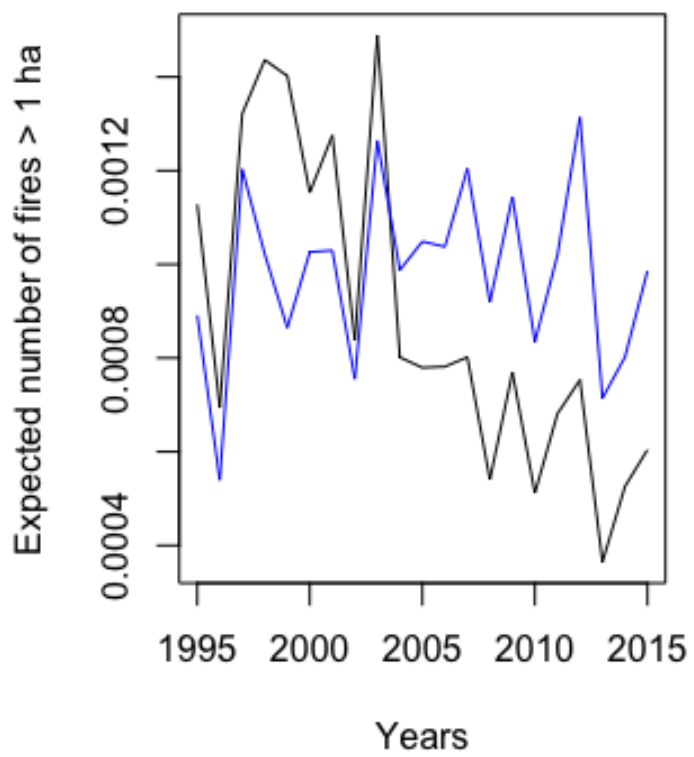

Figure 6 - Expected mean number of fires above 1 ha burnt area over the full Prométhée zone, per year and per pixel. Observed values are in black while simulated values are in blue.

We see that the model reproduces well the interannual pattern attributable to climate variations, as peaks and valleys of the simulated occurrence (in blue) most often occur for the same years than the actual data (in black). However, the model fails to take into account the evolution between pre- and post-2003 periods. The observed decrease in actual fire densities over time while simulated data remained fairly constant suggests an improvement in prevention and fire suppression policies in France since 2003, a historical year in terms of wildfires in France. This improvement in the last decade could be otherwise falsely interpreted as a result of less fire-prone climatic period.

\subsection{Projecting potential wildfire occurrence increase in the future}

The last step of our approach consists in projecting the expected fire occurrence (trend and uncertainty) in future climate using the statistical model we built for climate-fire relation. The benefit of this approach is that the fire number (occurrence) is an additive meaningful metric of fire activity, which can readily be integrated over time and space, contrary to FWI which requires the definition of subjective thresholds for its interpretation.

We used daily FWI series for the period 2080-2100 given by climatic models to predict the expected numbers of fires according to our model. The first results integrated over the Mediterranean area partly reproduce the intra annual distribution of wildfires observed in the past, with a first peak of fires in early spring and a second one in summer (Figure 7). The summer fire occurrence increases remarkably, probably because of the sharper increase of FWI values expected in summer (compared to the other seasons). 


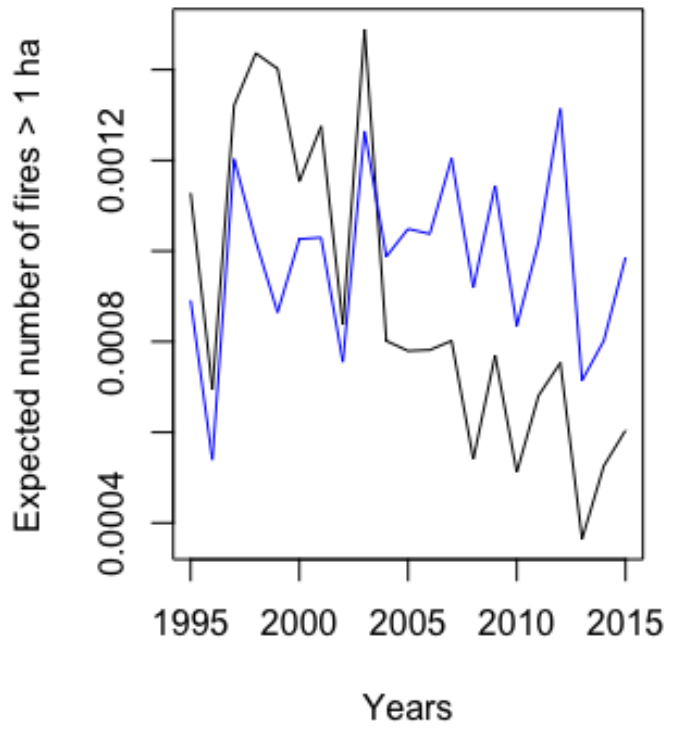

Figure 7 - Expected mean number of fires above 1 ha burnt area over all Promethee zone per year and per pixel $\left(8 * 8 \mathrm{~km}^{2}\right)$. Current observed values (1995-2015) are in black while projected values (model CNRM RCA4, scenario rcp8.5, 2080-2100) are in red. The model predicts an increase in summer fire occurrence. Winter fire occurrence remains stable for this time horizon.

\section{Discussion and perspectives}

Figure 8 shows the contributions of the different sources of uncertainty associated with climate projections of the seasonal mean FWI to the total variance (Figure 8, left) and compares them to the results that Hawkins and Sutton (2009) reported, for the global, decadal mean air temperature (Figure 8 , right). It is worth noting that the scenario uncertainty at the end of the century dominates for both variables, but that the air temperature exhibits far less intrinsic variability (and negligible from 2050) and far more model spread (dominant until 2050) than the FWI. In other words, it is not appropriate to use uncertainties on weather variables provided by climatologists when looking at projections of a specific climate impact such as wildfire danger. The FWI is a non-linear combination of weather variables, hence we should expect such differences to arise.
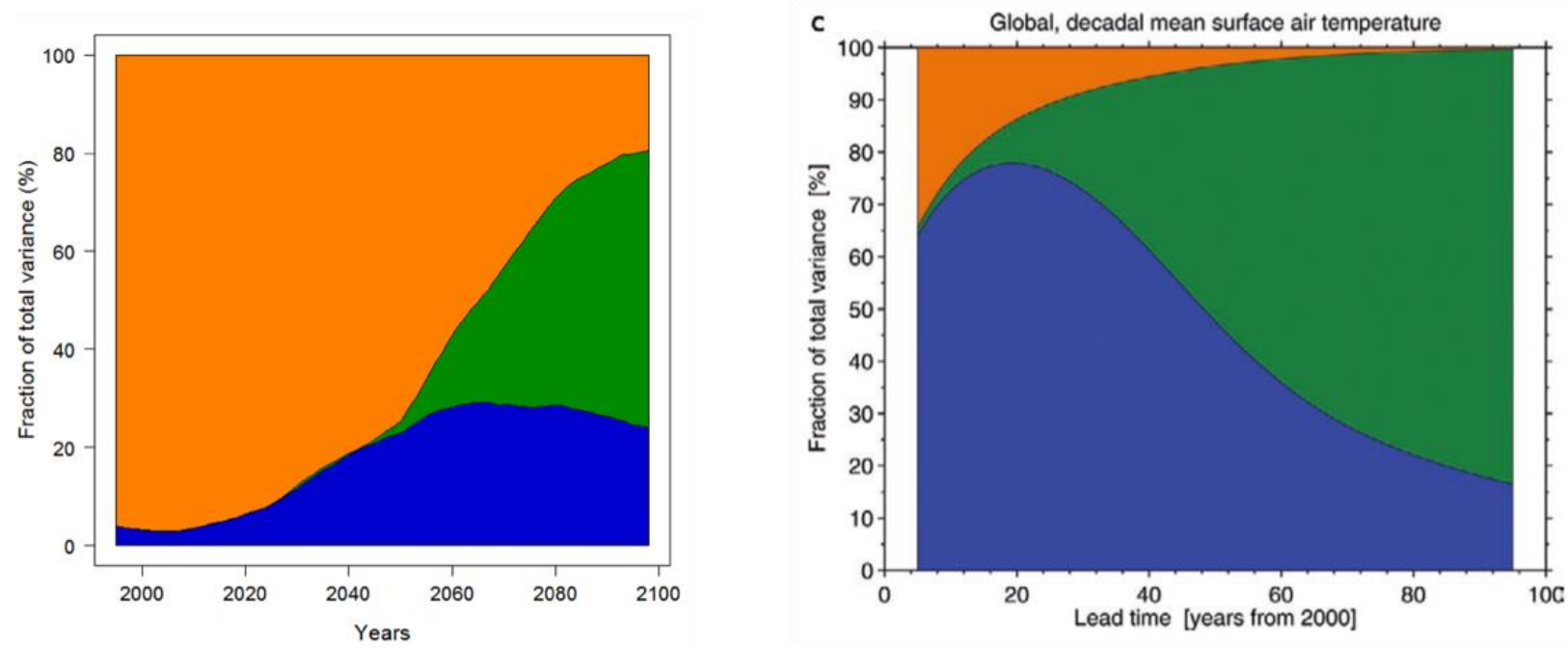

Figure 8 - Contributions of the different sources of uncertainty associated with climate projections of the seasonal mean FWI values (left) and global decadal mean temperatures (right) to the variance.

The fact that for FWI projections the scenario uncertainty overwhelms the other sources of uncertainty at the end of the century, demonstrates the importance of implementing climate policies to avoid a dangerous path in terms of wildfire danger. The result is particularly important because, in 
contrast, intrinsic variability dominates during the first decades up to 2050 and could hide the reality of the mean growing fire danger trend.

Our model performs well to highlight the explanatory power of the FWI as a predictor of past fire occurrence. The non-linear form of the curve confirms the issue arising when averaging FWI over space or time as a metric of future fire danger. This issue is related to, but should not be confounded with, the issue addressed in the FWI System with the proposed Daily Severity Rating (DSR). The DSR is an exponential transformation of the FWI and is supposed to be in more direct proportion to the work required to suppress a fire, but it does not correct a statistical bias. Yet, the Seasonal Severity Rating (SSR), which has been used in some projection studies (e.g. Amatulli et al. 2013; Bedia et al. 2014a), is the average of the DSR over the fire season and is more suitable for averaging than the FWI (Van Wagner 1987). In other words, it makes sense to average fire control effort, not fire danger rates.

Ongoing work integrates the development of a proper metric to compare the uncertainties arising from the climate model projections with those arising from the statistical model of expected fire occurrence.

Among the limitations of our projection method, it is applied here to fire occurrence which is not the best metric for fire risk interpretation. Similar work on burnt area is much more challenging, as burnt areas are more variable than occurrences. Another limitation is the fact that the occurrence model is fitted on the South-East of France in which fire datasets are available and in which fire occurs more frequently than in other regions. Projecting the model to whole France would be of high interest as fire-prone areas are expected to expand to the north owing to climate warming (Chatry et al. 2010), but this raises several problems, since many factors strongly vary among French territory, like land use and land cover, forest structure, population density, fire suppression policies. Yet we could project a potential fire number using the FWI partial effect $g(F W I)$ estimated in our occurrence model and bracket the projected values by uncertainties associated with other fire drivers.

To get more mechanistic insights into the drivers of fire that are hidden behind the FWI, it would be relevant to assess the relative contribution of the different sub-component of the FWI (DC, DMC, FFMC...) to the fire occurrence and burnt area. This would also help to evaluate spatially which components of climate change are responsible for the increase in FWI and fire danger and thus help to develop appropriate mitigation/adaptation strategies.

Finally, the statistical model for fire occurrence was initially developed for climate change impact studies, but it could be used for operational purposes at the scale of the South-East France as well, after cross-validation and testing over some evaluation period. Indeed, daily forecasts of fire numbers would be of a higher value to fire managers than a fire danger rate.

\section{Conclusion}

We propose a methodology to assess the impact of climate change on forest fire occurrence in French Mediterranean area. This method allows a quantitative assessment of the different uncertainties associated with the climate projection. The statistical model we develop enables us to transform predictions of FWI into expected numbers of fires and reproduces accurately observed patterns of past fire activity. Disentangling the effects of climate and other spatial-temporal effects has seldom been done in the French Mediterranean area and provides insights on the FWI limitations as well as on interesting spatial effects. The predictive ability of the model under changing climate is still to be considered with caution, due to the correlation existing between the different factors governing fire occurrence and severity, that might change under a changing climate and time period. The model for fire occurrence, after proper testing, could provide daily forecasts of fire numbers in the French Mediterranean area. 


\section{Acknowledgements}

Acknowledgements are expressed to the French Ministry of Agriculture which funded the research activities.

\section{References}

Amatulli, G., A. Camia, and J. San-Miguel-Ayanz. 2013. 'Estimating Future Burned Areas under Changing Climate in the EU-Mediterranean Countries'. Science of The Total Environment 450-451 (April): 209-22.

Bedia, J., S. Herrera, A. Camia, J. M. Moreno, and J. M. Gutiérrez. 2014. 'Forest Fire Danger Projections in the Mediterranean Using ENSEMBLES Regional Climate Change Scenarios'. Climatic Change 122 (1-2): 185-99.

Bedia, J., S. Herrera, and J. M. Gutiérrez. 2014. 'Assessing the Predictability of Fire Occurrence and Area Burned across Phytoclimatic Regions in Spain'. Natural Hazards and Earth System Science 14 (1): 53-66.

Brillinger, D. R., H. K. Preisler, and J. W. Benoit. 2003. 'Risk Assessment: A Forest Fire Example'. In Institute of Mathematical Statistics Lecture Notes - Monograph Series, 177-96. Beachwood, OH: Institute of Mathematical Statistics.

Chatry C., Le Quentrec M., Laurens D., Le Gallou J-Y., Lafitte J-J., Creuchet B. 2010. Rapport de la mission interministérielle 'Changement climatique et extension des zones sensibles aux feux de forêts'. CGAER-CGEDD-IGA. 89 p.

De Cáceres, M., N. Martin-StPaul, V. Granda, and A. Cabon. 2017. Meteoland: Landscape Meteorology Tools. R Package Version 0.6. 4.

Good, P., M. Moriondo, C. Giannakopoulos, and M. Bindi. 2008. 'The Meteorological Conditions Associated with Extreme Fire Risk in Italy and Greece: Relevance to Climate Model Studies'. International Journal of Wildland Fire 17 (2): 155.

Hawkins, E., and R. Sutton. 2009. 'The Potential to Narrow Uncertainty in Regional Climate Predictions'. Bulletin of the American Meteorological Society 90 (8): 1095-1108.

Lindgren, F., and H. Rue. 2015. 'Bayesian Spatial Modelling with R - INLA'. Journal of Statistical Software 63 (19).

McSweeney, C. F., Jones, R. G., Lee, R. W., \& Rowell, D. P. 2015. Selecting CMIP5 GCMs for downscaling over multiple regions. Climate Dynamics, 44 (11-12), 3237-3260.

Moriondo, M., P. Good, R. Durao, M. Bindi, C. Giannakopoulos, and J. Corte-Real. 2006. 'Potential Impact of Climate Change on Fire Risk in the Mediterranean Area'. Climate Research 31 (June): 85-95.

Preisler, H. K., D. R. Brillinger, R. E. Burgan, and J. W. Benoit. 2004. 'Probability Based Models for Estimation of Wildfire Risk'. International Journal of Wildland Fire 13 (2): 133-42.

Rue, H., S. Martino, and N. Chopin. 2009. 'Approximate Bayesian Inference for Latent Gaussian Models by Using Integrated Nested Laplace Approximations'. Journal of the Royal Statistical Society: Series B (Statistical Methodology) 71 (2): 319-92.

Van Wagner, C. E. 1987. Development and Structure of the Canadian Forest Fire Weather Index System. Forestry Technical Report 35. Ottawa: Canada Communication Group Publ.

Vidal, J.-P., E. Martin, L. Franchistéguy, M. Baillon, and J.-M. Soubeyroux. 2010. 'A 50-Year HighResolution Atmospheric Reanalysis over France with the Safran System'. International Journal of Climatology 30 (11): 1627-44. 
Viegas, D. X., G. Bovio, A. Ferreira, A. Nosenzo, and B. Sol. 1999. 'Comparative Study of Various Methods of Fire Danger Evaluation in Southern Europe'. International Journal of Wildland Fire 9 (4): 235.

Wang, Xianli, B. M. Wotton, A. S. Cantin, M.-A. Parisien, K. Anderson, B. Moore, and M. D. Flannigan. 2017. 'Cffdrs: An R Package for the Canadian Forest Fire Danger Rating System'. Ecological Processes 6 (1). 